This item was submitted to Loughborough's Research Repository by the author.

Items in Figshare are protected by copyright, with all rights reserved, unless otherwise indicated.

\title{
'Do we look like boy racers?' The role of the folk devil in contemporary moral
} panics

PLEASE CITE THE PUBLISHED VERSION

http://dx.doi.org/10.5153/sro.1840

\section{PUBLISHER}

University of Surrey, the University of Stirling, the British Sociological Association and SAGE Publications Ltd. (c) Sociological Research Online

\section{VERSION}

AM (Accepted Manuscript)

\section{LICENCE}

CC BY-NC-ND 4.0

\section{REPOSITORY RECORD}

Lumsden, Karen. 2019. "'do We Look Like Boy Racers?' the Role of the Folk Devil in Contemporary Moral Panics”. figshare. https://hdl.handle.net/2134/11669. 
This item was submitted to Loughborough's Institutional Repository (https://dspace.lboro.ac.uk/) by the author and is made available under the following Creative Commons Licence conditions.

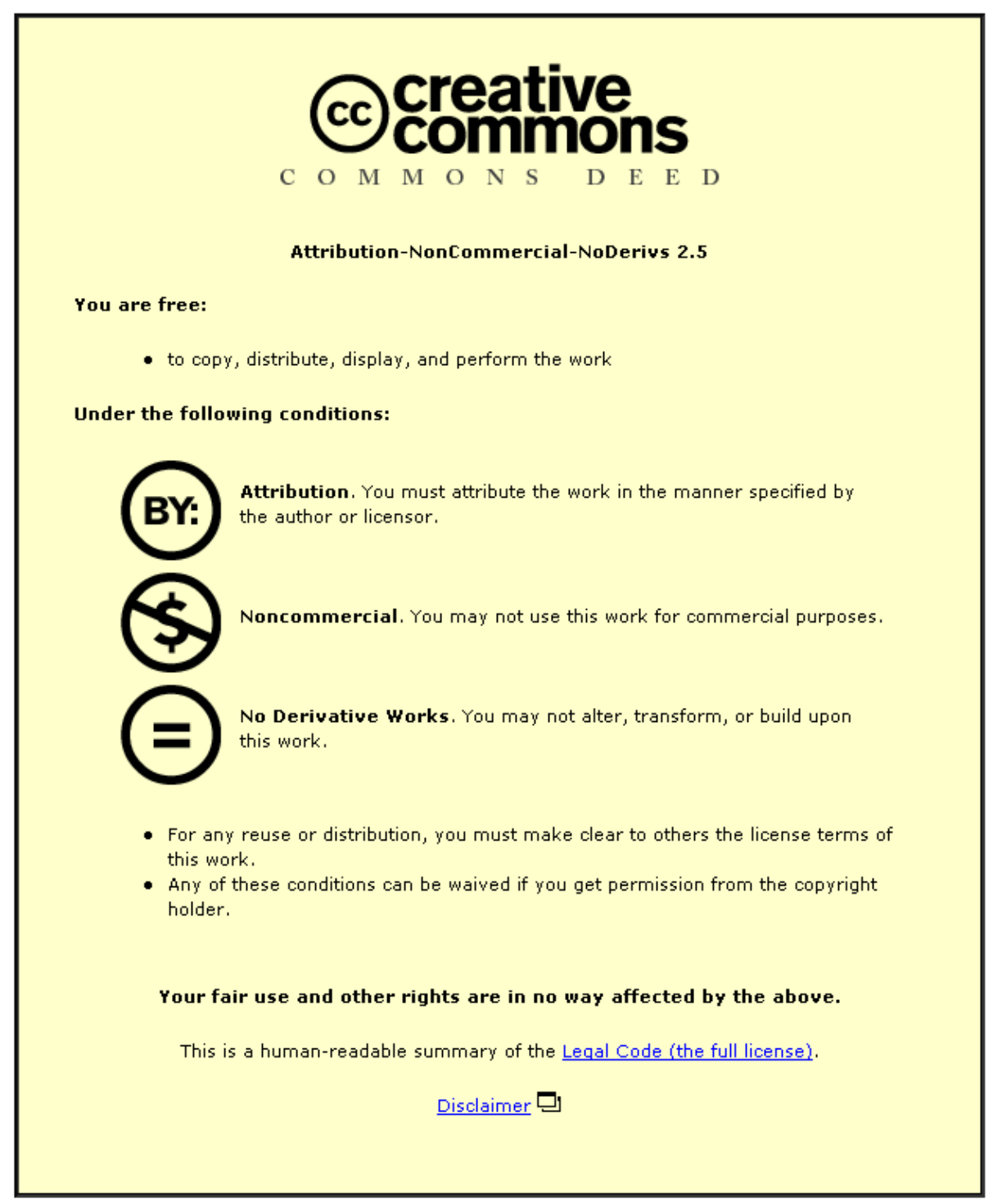

For the full text of this licence, please go to: http://creativecommons.org/licenses/by-nc-nd/2.5/ 


\title{
'Do We Look Like Boy Racers?' The Role of the Folk Devil in Contemporary Moral Panics
}

\begin{abstract}
This article addresses the failure of studies concerning moral panics to take into account the reaction of those individuals who are the subject of social anxiety. It responds to the suggestion by McRobbie and Thornton (1995) that studies of moral panic need to account for the role played by the 'folk devils' themselves, for a moral panic is a collective process (Young, 2007). The paper presents findings from ethnographic fieldwork with the 'boy racer' culture in Aberdeen, qualitative interviews with members of 'outside' groups, and content analysis of media articles. The societal reaction to the 'boy racer' subculture in Aberdeen is evidence of a contemporary moral panic. The media's representation of the subculture contributed to the stigmatization of young drivers and the labelling of the subculture's activities as deviant and anti-social. The drivers were aware of their negative portrayal in the media; however their attempts to change the myth of the 'boy racer' were unsuccessful. Although subcultural media can provide an outlet of self-expression for youths, these forms of media can also become caught-up in the moral panic. Ironically the youths' own niche and micro media reified the (ir)rationality for the moral panic.
\end{abstract}

\section{Keywords}

Boy racers; car cultures; ethnography; media; moral panics; subcultures; youth 


\section{Introduction}

This paper focuses on the media representation of the 'boy racer' subculture in Aberdeen and the reaction of young car enthusiasts and modifiers to their labelling as deviant and anti-social. The societal reaction surrounding the 'boy racer' subculture provided evidence of a localised moral panic. Stanley Cohen's (2002[1972]) book, Folk Devils and Moral Panics, remains a classic example of how groups such as youths are labelled by the media and other outside groups. More recent work by Cohen (1985) and Young (2007) also illustrates the continuing relevance of the concept of moral panic for understanding the social reaction to crime, deviance and difference in contemporary Western society. This paper recognises that a moral panic is a collective process involving the media, authorities, government, public and youths themselves (Young, 2007). However the discussion that follows focuses specifically on the local media's representation of the drivers, and the reaction of these drivers to the label of 'boy racer'. The media's representation of the 'boy racers' was similar to the representation of the Mods and Rockers in Cohen's (2002[1972]) classic study. The symbol of the 'boy racer' has come to represent deviance, dangerous driving and anti-social behaviour. McRobbie and Thornton (1995) argue that forms of subcultural media provide an outlet for 'folk devils' to defend their interests. However this paper will demonstrate that these forms of media themselves become caught-up in the moral panic. The subculture's use of the Internet and the moral indignation expressed by outside groups with regards to their use of the Internet also demonstrates the virtual aspect of contemporary moral panics.

The first section of this paper discusses the 'boy racer' phenomenon and in particular Aberdeen's 'boy racer' subculture. The next part of the paper outlines the 
methodology utilised in order to study Aberdeen's 'boy racer' culture and the related societal reaction to their behaviour. The latter half of this paper contributes to the concept of 'moral panics' by discussing the local media's representation of the subculture and their creation and maintenance of the myth of the 'boy racer'. It then analyses the subculture's reaction to their representation in the media. This includes their rejection of the label of 'boy racer' and their attempts to change the media's portrayal of them as deviant and anti-social. However in their rejection of the boy racer' myth they ironically help to reinforce it by labelling certain members of the subculture as 'boy racers'. They attempt to normify their own conduct while attributing deviant or anti-social behaviour to those individuals who fit the myth of the 'boy racer'.

\section{Aberdeen's 'Bouley Bashers'}

In contemporary Western society car cultures are an increasingly popular leisure pursuit amongst adolescents. Known in the UK as 'boy racer' culture, the image of a young male driving a modified car with a spoiler, alloys, lowered suspension, and a loud exhaust and stereo system, has permeated the public imagination. As a collective cultural practice, the 'cruising scene' developed out of unauthorised cultural gatherings of young people in modified cars, that occurred in retail parks and industrial estates late at night during the 1990s (Bengry-Howell, 2005). These gatherings provide an outlet for youths who wish to socialise with like-minded car enthusiasts, drive around, and show off their cars and driving abilities. On occasion, these spaces are also home to illegal activities such as speeding and street racing. Although this is a largely male-dominated culture, a growing number of females now participate and are as passionate about their cars as the boys. 
These gatherings and the car modifier have been presented as a social problem by the authorities and the media. 'Boy racers' are one of the early twenty-first century's 'folk devils' (Cohen, 2002). Fuelled by media coverage of reckless, irresponsible, and antisocial driving, young motorists are an area of concern for politicians, police, and citizens more generally. The illegality of the subculture is implied through accusations of dangerous and anti-social driving including, most notably, illegal street racing, speeding, exhibitionist behaviour (such as 'wheel spins', 'doughnuts' and 'burn-outs') and behaviours defined as 'anti-social', such as noisy exhausts and car stereos, revving engines, and the ways in which they modify their cars. The mere presence of the subculture is viewed as a threat by local residents and the authorities. 'Boy racers' are 'matter out of place' (Douglas, 1966). Many environmental nuisances condemned as anti-social - and increasingly subject to special punitive measures - illustrate how changing technology and commerce help to create new challenges to tolerance (Burney, 2005: 78). The urban space in Aberdeen, like many other seafront towns across the UK, has been presented as a 'contested arena' in which adults are asked to assume that young people have lesser rights (Aitken, 2001).

The Beach Boulevard, a quarter-mile stretch of road, is the main thorough-fare from the seafront to the centre of Aberdeen, and forms part of the drivers' 'cruising' circuit. The 'boy racer' culture in Aberdeen, known locally as the 'Bouley Bashers', have occupied Aberdeen's seafront since the 1960s. The Beach Boulevard (which was completed in 1960) was likened to 'Brands Hatch Race Circuit' by local residents in 1972. Proposals for dealing with the drivers were put forward in 1980 by a local councillor who claimed that speeding drivers on the Boulevard were 'mindless 
morons' and suggested putting down sleeping policemen to deter them and in 1984 a councillor proposed closing the Beach Boulevard to stop speeding youths. ${ }^{1}$ Although residents claimed that the 'boy racers' have been a problem since the $1960 \mathrm{~s}$, the local media remained silent on the topic until 2000 onwards when the area underwent vast redevelopment which included residential and retail complexes. As Becker (1963) notes, moral crusades are typically dominated by those in the upper levels of the social structure. The increase of middle-class residents to the area contributed to increased pressure on the authorities to act against the 'boy racers'. This influenced the media's interest in the issue and the actions of politicians, council officials and the police. From 2000 onwards, concern over illegal street racing and anti-social behaviour resulted in a proliferation of media articles centred on the detrimental effects the 'boy racers' had on the environment, and the lives of local residents. As one local newspaper wrote:

For more than 30 years they've been at it - speeding recklessly up and down the Beach Boulevard...The leisure complex has grown massively and become a magnet for families. But that hasn't stopped the madness of the boy racers - or led to the authorities driving them off the road. ${ }^{2}$

A number of measures were introduced in order to control and regulate their use of the urban environment. This included altering the road layout and traffic system, installing CCTV cameras, enforcing parking restrictions and proposing to close the Beach Boulevard at night. New powers were also introduced under the Antisocial Behaviour etc. (Scotland) Act (2004). ${ }^{3}$ However the efforts of various 'outside' 
groups have proved largely unsuccessful in deterring the drivers from Aberdeen's seafront. Thus, the moral panic concerning Aberdeen's 'boy racers' erupted suddenly in 2000 and became a regular focus for the local media. Goode and Ben-Yehuda (1994) claim that moral panics are volatile - they will erupt suddenly and disappear just as quickly. In this instance however, media attention concerning Aberdeen's ‘boy racers' was extensive (spanning nearly seven years).

\section{The Research Participants}

The city of Aberdeen formed the setting for a doctoral study into 'boy racer' culture, and the societal reaction to their behaviour, from September 2005 to September 2008. Access to the subculture in Aberdeen was aided by Grampian Police who regularly met with a group of drivers from the beach area of the city. These Drivers' Group meetings took place every three months and were attended by a Neighbourhood Officer from Grampian Police and drivers from the beach area of the city. The police officer who organised these meetings introduced me to Debbie, the main representative from the Drivers' Group. She became my initial gatekeeper to the setting and was essential in helping me negotiate access to the group. Debbie introduced me to the setting and her friends, and provided vital information to guide me though participant observation in that environment. She introduced me to Robert, my second gatekeeper, who hosted a website centred on Fiats and also attended Drivers' Group meetings.

Most participants in Aberdeen's 'boy racer' subculture were male and aged between 17 and 25 years old. However some participants were aged over 25 and a growing number of females participate in the subculture either as 'girl racers', girlfriends of 
the 'boy racers', passengers in cars, or as 'bikini girls' or 'babes'. ${ }^{4}$ Debbie was in her early thirties and regularly participated in the subculture. She attended gatherings at Aberdeen's seafront on most weekends, represented the subculture at Drivers' Group meetings, hosted a website centred on car modification and organised car shows in Aberdeen. Thus Debbie played a central role in the subculture. Debbie related her participation in the culture to an influence from male members of her family who were interested in cars: 'It's just like most people. I have a general interest in cars. Anything with an engine really! Like when I was young I came to the beach with my uncle and I watched him fix cars'.

For Robert, participation in the culture was also related to his childhood:

When I was about sixteen I worked in a car showroom. I was the only one who cleaned up all the cars, washed them, polished them. If I worked really hard I could get round the whole yard in a day. Just plugged in my headphones, listened to music, and away I went...but from an early age I was interested in cars in some way I guess. I mean, when I was around four or five I used to have a make-believe friend car that lived in the cupboard at the bottom of the stairs [laughs]. So I guess I've always shown an interest in them.

Robert was 24 years old and had regularly participated in the subculture for over four years. He attended gatherings at Aberdeen's seafront, hosted a website centred on Fiats, and attended Drivers' Group meetings. The other participants who were 
interviewed during the course of the research were friends of Debbie or Robert and attended gatherings at Aberdeen Beach.

\section{Methodology}

In order to investigate the 'boy racer' culture in Aberdeen, the research employed ethnographic methods, which allowed an in-depth look at the everyday lives of its members, the reasons, feelings, and justifications for their actions, and for their participation in the subculture. In total 150 hours were spent with the group over a one-year period, from September 2006 to August 2007. The role of overt participant observer was adopted. During the fieldwork period I spent weekend evenings in the main setting - Aberdeen Beach. I attended Drivers' Group meetings and car shows, one of which was organised by the Drivers' Group and the other by Fast and Modified magazine. I also attended an Italian car show in St Andrews and four meetings (referred to as 'meets' or 'cruises') across Scotland organised by the Fiat group. The fieldwork also involved socialising with members of the group to celebrate events such as birthdays, as well as accompanying them to scrap-yards, garages and shops to search for car parts. Internet sites which were created and utilised by participants were also a source of data collection.

Research also consisted of semi-structured interviews with members of the subculture (which were recorded and transcribed). Eight members of the subculture were interviewed in addition to one former member of the subculture. Debbie was the only female who agreed to an interview. With the exception of Debbie, the interviewees were all aged between 20 and 25 years old. Interview questions were written up in advance of each interview however the context of the interview was such that 
respondents were allowed to deviate from the interview schedule in order to discuss other issues they felt were relevant. Interview questions covered the following topics: participation in the subculture and reasons for participation, their cars, the outside groups, the use of anti-social behaviour legislation and road traffic legislation, and their views of other participants. Respondents were approached towards the end of the fieldwork and asked to participate in an interview. However some members of the culture were unwilling to participate and although they knew me, some were suspicious of the motivations for my research. For instance Robert would not let me record the interview and requested to see my notes afterwards. Therefore it proved easier to collect data on participants' opinions and viewpoints via informal chats which took place during participant observation.

Lee (1993) argues that respondents who are part of a stigmatized group are likely to be suspicious of outsiders. Deviant cultures have little to gain by allowing researchers access to their daily lives and various illegal activities (Winlow et al. 2001: 538). Moreover, if access to deviant cultures is gained, deviant activities can be obscured from view by what Best and Luckenbill (cited in Lee, 1993: 133) refer to as 'command of place'. By means of physical separation and the use of shielding mechanisms, participants free themselves from surveillance by social control agencies and in doing so they protect themselves from the unwitting and the curious, and present barriers to the researcher' (Lee, 1993: 133). The group's reluctance to participate in the research may have been linked to the tendency for the media to misrepresent and mis-quote group members. They did not trust the local media, due to the negative coverage they had received in the past. For instance in the Press \& Journal it was claimed: 'Last night drivers were defensive about the scheme and were unwilling 
to speak to the media, claiming that they did not want their comments to be "twisted". 5 As a result, participants seemed suspicious of the motivations for my research and at the beginning of the fieldwork Robert jokingly accused me of being 'a spy for the authorities'. Respondents may also have feared being categorized or labelled negatively and thus were keen to emphasise to me that they were not involved in deviant or anti-social activities.

In addition to the drivers, I also conducted semi-structured interviews with members of the outside groups. This included interviews with four officers from Grampian Police, a local councillor, MP and MSP, three journalists, two council officials, individual interviews with two residents and a focus group interview with four residents present.

More than two hundred local and national media articles which focused on the socalled 'boy racer' subculture in Aberdeen and the measures introduced or proposed to regulate their behaviour, were also collected and analysed. Articles were collected between August 2003 and September 2007 from local newspapers including two daily newspapers: the Press and Journal and the Evening Express; and two free newspapers distributed weekly across Aberdeen: the Independent and the Citizen. Relevant articles from national media outlets such as $B B C$ News, The Times, The Guardian and The Scotsman were also collected during this period. Official documents from Aberdeen City Council and data provided by Grampian Police in relation to road traffic offences and the use of anti-social behaviour legislation in Aberdeen were also analysed. The societal reaction to the subculture was analysed using the concept of 'moral panic'. The next section briefly discusses this concept and its criticisms. 


\section{The Sociology of Moral Panics}

Stanley Cohen (2002[1972]) and Jock Young (1971) were the first to systematically use the concept of 'moral panic' in their studies of societal reactions to deviance. Their edited collections developed and effectively launched the concept of moral panic (McRobbie and Thornton, 1995: 560). Using Becker's (1963) interactionist approach to the study of deviance and a model of collective behaviour derived from disaster research, Cohen (2002[1972]) illustrates how the media played an important role in creating a moral panic with regards to the Mods and Rockers. According to Cohen (2002[1972]: 1):

Societies seem to be subject, every now and then, to periods of moral panic. A condition, episode, person or group of persons emerges to become defined as a threat to societal values and interests; its nature is presented in a stylized and stereotypical fashion by the mass media; the moral barricades are manned by editors, bishops, politicians and other right-thinking people; socially accredited experts pronounce their diagnoses and solutions; ways of coping are evolved or (more often) resorted to; the condition then disappears, submerges or deteriorates and becomes more visible.

For Cohen (2002[1972]: 30) the most important factor is how the media came to interpret and present the situation for 'it is in this form that most people received their pictures of both deviance and disasters' and 'reactions take place on the basis of these processed or coded images'. Goode and Ben-Yehuda (1994) characterise a moral panic as consisting of five elements. These are: 'concern' over the behaviour of a 
particular group and its consequences; 'hostility' towards the group in question; 'consensus' that the threat is real and caused by the specific group; 'disproportionality' where the assumption is that more individuals are involved in the deviant behaviour; and 'volatility' since a moral panic may erupt suddenly and disappear just as quickly as it appeared (Goode and Ben-Yehuda, 1994: 33-34).

Young people are most frequently the subject of moral panics and youth subcultures are regularly blamed by the media for deviant acts (see Presdee, 2000). Categories of youth such as 'punks', 'ravers', 'chavs', 'hoodies', 'skinheads', 'skaters', 'goths', 'emos', and 'boy racers', continue to be a topic of concern and debate for the moral guardians of society. Youths continue to be portrayed as disorderly, dangerous and anti-social by the media.

The recent work of scholars such as Young and Cohen illustrates the continuing relevance of the concept of moral panic for understanding the societal reaction to different or marginal groups. This involves taking note of changes in society and in the politics of crime and deviance. Young (2007: 62) argues that there has been a radical shift in society from one which was comparatively stable in terms of work, family and community, to one in which all three of these 'girders of ontological security have become unsteady, less substantial and frequently broken':

If the moral panic upon entering the Golden Age was about a world of austerity and discipline slipping away, the moral panic this side of the Golden Age is of prosperity and security slipping away. It is a time of 
middle-class vertigo, of uncertainty, of a fear of failing (Young, 2007:

$62)$.

In this setting, panics and scapegoating focuses on the socially excluded, for instance the 'triptych of welfare scrounger, immigrant and drug addict, frequently elided and radicalised, and to which, after $9 / 11$, a further refracting mirror has been added: that of actual and imaginary terrorist' (Young, 2007: 63). The social world of the USA and other societies at the beginning of the twenty-first century is one of a "pervasive insecurity' that has been described in terms of a 'culture of control', 'culture of fear', and 'governing through crime' (Feeley and Simon, 2007). In this social world moral panics are part of the infrastructure of contemporary society, so much that the degree of specific episodes of real or imagined violence is of no real salience (Tyler and Boeckmann, 1997). Media and law enforcement have worked to internalise control over the production of insecurity. Thus, moral panics have become part of the 'manufactured background, a feature of the larger order of knowledge and power that never goes away or recedes, and that must be constantly guarded against' (Feeley and Simon, 2007: 51). Governments in the last decade have increased state involvement by extending the boundaries of the criminal law. This involves criminalising areas of behaviour not previously the subject of the criminal law, or increasing either police powers or state control of the police (Reid, 2003). For instance the Public Order Act (1986) criminalised conduct perceived to be disorderly or threatening and as a result criminalised diversity and dissent (Reid, 2003: 87). The provisions that did this were those relating to travellers; aggravated trespass; trespassory assemblies; and ravers. The Antisocial Behaviour Order (ASBO) which was introduced under the Crime and Disorder Act (1998) is a further instance of this with what was previously perceived 
as merely socially offensive now being perceived as anti-social and subject to criminal liability (Reid, 2003).

\section{The Critique of Moral Panics}

Social scientists have criticised the concept of moral panic for a number of reasons. For instance, McRobbie and Thornton (1995) argue that moral panics are harder to constitute than they once were while others argue that there is now "increasing rapidity in the succession of moral panics' and an 'all-pervasive quality of panics that distinguish the current era' (Thompson, 1998: 2). The term moral panic is also now regularly used by journalists to describe a process which 'politicians, commercial promoters and media habitually attempt to incite' and now 'even the media themselves are willing to take some of the blame' (McRobbie and Thornton, 1995: 559-560). Moral panics have become a standard response and the method by which daily events are brought to the attention of the public (McRobbie and Thornton, 1995: 560). The media is no longer separable from society and instead, 'social reality is experienced through language, communication and imagery with social meanings and social differences becoming inextricably tied up with representation' (McRobbie and Thornton, 1995: 570).

It has also been posited that the concept of moral panic be revised in terms of new sites of social anxiety which have emerged alongside them; namely those sites of the political potential of catastrophes bred in a risk society (see Hollway and Jefferson, 1997). Ungar (2001) claims that new sites of social anxiety emerging around nuclear, chemical, environmental and medical threats have thrown into relief many of the questions motivating moral panic research. According to Hier (2003: 4) 'a heightened 
sense of risk consciousness commonly associated with uncertainties of late modernity has given rise to a process of convergence whereby discourses of risk have conjoined with discourses containing a strong moral dimension'. For Jenkins (1999), mistrust of experts opens up reflexive orientation between victims and the authorities.

A further critique is the tendency for studies to neglect the role played by the 'folk devils' themselves. According to Young (2007: 56):

What is missing is both the sense of energy and intensity of this happening and that, rather than a one-way process, this is a collective endeavour, for the youth, the media, the moral entrepreneurs, the control agents and the public are, so to speak, accomplices in the action.

McRobbie and Thornton (1995) argue that folk devils are less marginalized than they once were and as well as being articulately supported in the same mass media that castigates them, their interests are defended by their own niche and micro-media. Future studies of moral panic need to take into account the attitudes and activities of different social groups and organizations which should not be subsumed under a consensual 'society' (McRobbie and Thornton, 1995). The disparate perspectives of different niche, mass and micro-media must be explored because 'so-called folk devils now produce their own media as a counter to what they perceive as the biased media of the mainstream' (McRobbie and Thornton, 1995: 568). 
This paper adds to studies of moral panic by analysing the reaction of drivers to their labelling as 'boy racers' and the moral panic surrounding the subculture. It is acknowledged that a moral panic is a collective process involving the media, residents, government, authorities, public and youths, however this paper focuses on the media representation of 'boy racers' and the reaction of the drivers to this representation.

\section{The Myth of the 'Boy Racer'}

The local media's representation of the 'boy racers' can be seen as contributing to a moral panic. This moral panic has also occasionally surfaced in the national media with the reporting of incidents involving 'boy racers' in other seaside towns across the UK such as Plymouth and Brighton, and in other countries including Sweden, Iceland, New Zealand and Australia. The local media's representation of the 'boy racer' was analysed using the themes of exaggeration and distortion, prediction and symbolization (see Cohen, 2002[1972]).

There was over reporting of the activities of 'boy racers' in terms of exaggerating the seriousness of events, the number taking part, the number involved in deviant behaviour, and the amount and effects of deviant or illegal behaviour. The mode and style of presentation in media reports were characteristic of crime reporting. This included sensational headlines, melodramatic vocabulary, and a deliberate heightening of those elements described as news. Misleading and dramatic headlines were used, as was the generic plural and reporting the same incident numerous times. For instance local media articles reported that there were 'scores of young drivers'. 6 The subculture was referred to as a 'crew'. The 'boy racer' phenomenon was a 
problem that was 'spreading' across towns and cities in the UK. Their driving was also exaggerated by references to 'excessive' or 'extreme' speeds, and 'roaring' or 'madly revved' engines. ${ }^{7}$ Phrases and words were also used to exaggerate the action taken against the 'boy racers'. Anti-social behaviour had to be 'slashed'. ${ }^{8}$ Measures were portrayed as a war or battle with residents "celebrating victory' ${ }^{9}$ over the 'boy racers'. Police operations were referred to as a 'blitz', 'campaign' or 'crackdown'. The residents and drivers are referred to as 'rivals" ${ }^{10}$, coming 'head-to-head'11 with one another at community meetings. 'Weapons' would be used in the 'Bouley War'. ${ }^{12}$

The road used by the drivers - the Beach Boulevard, is referred to as 'notorious' and 'infamous'. ${ }^{13}$ 'For years residents living alongside the Boulevard have been plagued by boy racers using the strip as their private playground, playing loud music and revving their engines'. ${ }^{14}$ The drivers have 'colonised this leisure sector of the Granite City, rendering it uninhabitable in the evening for anyone who does not thrill to the souped-up excesses of the internal combustion engine'. ${ }^{15}$ Its reputation was conveyed in the ITV series, 'Drivers from Hell' (2002), where Aberdeen's Beach Boulevard was named as the worst area in the UK for illegal street racing. Local media reports predicted that the 'boy racers' would continue to use the Beach Boulevard and they were referred to as a 'problem that just won't go away'. ${ }^{16}$ A local councillor referred to the Beach Boulevard as a 'mechanical catwalk' of 'souped-up cars'.

Negative symbols were used to refer to the drivers at Aberdeen Beach who preferred to be known as 'car modifiers' or 'car enthusiasts'. The car enthusiast or modifier was portrayed as a 'boy racer'. The image of the 'boy racer' becomes symbolic of deviance and anti-social behaviour (especially though their use of the car and public 
roads). The modified or 'souped-up' car in turn symbolizes the 'boy racer'. Thus the object of the car is symbolic of deviance, anti-social driving, racing or speeding. The status of rebellious, deviant youth is also linked to the notion of the 'boy racer'. Since the car enthusiast or modifier is portrayed and referred to as a 'boy racer', they themselves become symbolic of deviance, danger and anti-social behaviour.

The orientation of local media reports shifted while the council were debating the closure of the Beach Boulevard in 2006. An editorial comment in the Evening Express claimed:

The Beach Boulevard must not be closed because of boy racers. It is as simple as that. All a closure will achieve is to shift the problem elsewhere. It's already happening. Shutting the road will also send a clear signal that the police and the authorities are washing their hands of those who break the law. They would rather close a public highway than tackle the problem properly. If councillors endorse the closure today, then the Bouley Bashers will win and that cannot happen... ${ }^{17}$

For the media, closure of the Beach Boulevard would signal victory, not to the residents or politicians, but to the 'boy racers' themselves. It would be the citizens of Aberdeen who would lose out by the inconvenience of a road closure and it was suggested that the 'boy racers' would disperse to other areas of the city. In addition to condemning and stereotyping the 'boy racers', the media are also critical of the authorities for not doing enough to stop them. This is illustrated in an editorial comment from the Press \& Journal: 
Boy racers are not a new phenomenon; they have been a serious irritant for a number of years, particularly to those who are unfortunate enough to cross their paths. However in today's affluent society, there just happens to be more of them. This is particularly so in Aberdeen, where the 'Bouley Boys' have traditionally screeched around the Beach Boulevard area with apparent impunity while any restrictions imposed on them have had only limited success. Long-suffering local people have reached the end of their tether... The police and local authority need to remove this blight from the beach area once and for all by rooting out the hardcore troublemakers...Councillors appear to shrug their shoulders as if they have done enough; this is not an option. Efforts should be redoubled to solve the problem before the boy racers start driving something new; that is, driving visitors and businesses away from the beach area. ${ }^{18}$

It is important to note that newspapers react to public mood as much as they create it, despite their claims to the contrary. The local media did not create the moral panic on its own. It can only do so in combination with residents, the public, politicians, authorities, and youths themselves. However, by identifying and reporting on a political, controversial and entertaining topic, the media can sustain and shape the public's imagination with regards to the 'boy racer' myth. This is particularly so through the labelling of all car enthusiasts as deviant through association with the symbol of the 'boy racer'. Hence, the media can be seen as contributing to a moral panic regarding car enthusiasts at Aberdeen's seafront. 
Moreover, the spaces available to the subculture, for self-expression, are a topic of concern for the authorities and media. Deviant or illegal behaviour which relates to the motor car is irrationally linked to the myth of the 'boy racer'. This further perpetuates the idea that the car enthusiast is deviant, dangerous and has no respect for the law or public safety. Various forms of subcultural media are criticised by the local press for contributing to the 'boy racer' phenomenon. There was concern over Internet sites which were linked to the car culture in Aberdeen. The local press claimed that these websites were used to coordinate the activities of local drivers:

\begin{abstract}
A forum section is peppered with boasts about high-speed chases with police as part of a criminal 'hall of fame'. It also contains tips on highperformance modifications for cars, mechanical advice and sales information...Among the items posted on the site include boasts of 'racing' up the city's Westburn Road at $90 \mathrm{mph}$ and overtaking 'undercover cops' at $80 \mathrm{mph} .{ }^{19}$
\end{abstract}

Local police were reported as being aware of the websites but unconcerned. The press also reported that an ex-police officer, hiding behind the name, 'Graniteman', was using these websites to inform 'boy racers' on how to evade the law. Graniteman was reported to have informed members of an Internet site on the details of unmarked police cars, the penalties faced for traffic offences, and how to avoid being disqualified if they had committed a crime. ${ }^{20}$ As a result of media attention and pressure from residents and state representatives, many of these websites were shut down. A year later however, the Evening Express reported that two new websites had 
been set up. ${ }^{21}$ Residents were reported to be 'furious' about the new websites which they believed would encourage dangerous driving at the Beach Boulevard and 'destroy their hopes for a peaceful life'.

\section{Subcultural Reaction: 'Do We Look Like Boy Racers?'}

The purpose of this section is to illustrate that a 'moral panic' is a collective process involving not only the media, moral entrepreneurs, public and control agents, but the youths themselves (Young, 2007). Hence this section will discuss the drivers' views of the societal reaction, and in particular, their representation in media discourses. The car enthusiasts were aware of the media's negative portrayal of the car modifier. They continually made attempts to distance themselves from what they saw as the stereotypical 'boy racer'. Negative assumptions are attached to the 'boy racer' label. Included here is the assumption that 'boy racers' are young males who are primarily interested in tests of driving speed and skill, "who collectively seek to subvert the "normal" functions of public space' (Falconer and Kingham, 2007: 190). The drivers' attempts to change the representation of the car modifier or car enthusiast as a "boy racer', by the authorities, public and media, were largely unsuccessful. They were aware that these attempts would fail, especially with regards to the local media. Debbie was asked what she thought of the local media's reporting of the 'boy racers' at Aberdeen's seafront:

Recently it changed to be quite positive...aside from the headline about 'Bouley Boys', the article turned quite positive. But since then it's gone back to what it was before. That guy Frank Gilchrist wrote in his column a couple of weeks later that the residents should buy a huge 
ghetto blaster and blast us from the beach. I emailed him inviting him to Drivers' Group meetings so that he could find out what we're really about, but he didn't even have the guts to reply. I got a reply from someone else at the Evening Express asking permission to publish our email responses, so we said yes. But next thing they printed them edited with the positive stuff we said cut out. It made us look stupid. So it sounded like we were just complaining "we spend so much money on our cars, blah, blah, blah'. They cut out all the meaningful good stuff and made us look like moron boy racers again.

Debbie was also asked why she thought their coverage was so negative:

I think it's political cos they don't like the police, the council or us. So they make us look bad. They don't want a story that says: 'Car Enthusiasts Explain What Their Car Means to Them'. Instead they want something like 'Bouley Boys Cause Residents' Lives Misery'. That's going to sell more papers cos it's a scandal. Funny thing is though, for about the past three months, the same paper has been running a feature in the motor section called 'Show off Your Car' and I guarantee you that every single one of those cars you see at the beach. So it's hypocritical. They'll use us that way to fill in some page space but they're not interested in hearing our side of the story. 
Debbie recognised that attempts to put their side of the story across would fail since they were edited to fit the myth of the car enthusiast as a 'boy racer'. Debbie did not consider herself a 'girl' or 'boy racer' as the media liked to label them:

It's not what we're about and people need to understand that. A forty year old man who's interested in cars wouldn't appreciate that cos he's not a boy and maybe doesn't race. When you think of boy racer you think of a spotty little teenager in a cheap Corsa or Saxo. We're certainly not that. It's about coming here to socialise and cos you're interested in cars. You think of boy racer and you think of them driving up and down doing laps all night. None of us do that...It's just a label but it's what the public perception of us is, because groups say we're like that. If you tell someone you go down the beach at weekends they call you a boy racer. Or it's like being some kind of rogue, hoon, or a lout.

Instead, Debbie preferred to be referred to as a 'car enthusiast' because 'that's what the culture is all about'. She would have preferred the label of 'petrol head' or 'motor head' instead of 'girl racer'. As Debbie points out, they are viewed as 'boy racers' because of their association with Aberdeen's Beach Boulevard. She highlights the discrepancy between the 'boy racer' myth and those who are serious car enthusiasts. When asked what he thought of the 'boy racer' label, Robert highlighted the association between 'boy racers' and illegal street racing: 
Well it's stereotypical. Isn't it? I guess by their definition I typically am [a 'boy racer'] but then what does the term mean? I am, but I don't really race. In fact, not that I don't really race, I never have raced! Most people who come down here aren't racers either. It's just a few idiots who spoil it for the rest of us.

Brad is also keen to distance himself from the label of 'boy racer'. He claims that popular culture further exaggerates this stereotype and refers to a connection between the way people who attended raves in the early 1990s were stigmatized and how the so-called 'boy racers' are stigmatized:

People are afraid of us because of films like the Fast and the Furious. I don't think much of these films because people assume that's how we act and younger people try to modify their cars to look that way. It's like the stereotypical 'Bouley Basher' or 'boy racer' who wears a Burberry cap, has a lowered car and plays really loud music. It gives us all a bad name when all we want to do is socialise.

Brad believes that people fear the symbol of the 'boy racer'. For Debbie, this fear and misunderstanding is experienced through other motorists' reactions to her on the public roads. She claims that when driving, other motorists are inconsiderate towards her because her car is modified. They will not let her out at junctions and cut in front of her. Vicky also reiterated this and remarked: 'It's because they think we're boy racers, even us girls, they call us boy racers too. Do we look like we are?' 
Members of the subculture in Aberdeen were aware of their negative representation in the media and how this may in turn influence the public's perception of them. In their minds, the car modifier or car enthusiast was viewed by outside groups in the same way as a 'boy racer'. They believed that by owning and driving a modified car they were labelled as a 'boy racer' or 'girl racer'. However, in their recognition of the stereotype, and their attempts to distance themselves from it, they also identified members of the subculture whom they believed matched the 'boy racer' stereotype. This is evident in Robert's statement that 'it's just a few idiots who spoil it for the rest of us'.

\section{Bad 'Boy Racers': In-Group Deviants}

Members of the subculture shifted the blame for deviant or anti-social behaviour onto members of the subculture who behaved like a stereotypical 'boy racer'. Members of the subculture who did not follow subcultural norms and values were seen as 'outsiders' (Becker, 1963). These 'outsiders' were condemned both for their sheer presence as well as for their (deviant) behaviour (see Watt, 2006: 787). The drivers whom I spoke to viewed themselves as the legitimate members of the subculture. As well as attempting to change the myth of the 'boy racer' and their negative portrayal in the media, the drivers identified individuals whom they believed were stereotypical 'boy racers'. Paul acknowledged that deviant and illegal behaviour did occur at Aberdeen Beach however he was keen to distance himself from this behaviour:

Interviewer: Are there any kinds of illegal behaviours that go on here? 
Paul: Yes every night there's something happens. There's those folk that think its ok to race and speed. You see them doing laps all night long. But that's not what we're about. Most of us just want to sit on the trammers $^{22}$ and chat to our mates. We spend too much money on our cars to write them off by driving like idiots and I worked hard to earn my licence. Besides, I can't afford the petrol to be doing laps all night. It tends to be the same group of friends that don't behave. I've seen myself reporting their licence number to the police if they have been driving dangerously, swerving all over the road and cutting people up. It's not that I'm grassing or being a snitch but you can see an accident is going to happen and we don't want that, or our cars getting damaged. It doesn't make us look good. I think I've phoned in about seven times.

Interviewer: What type of people are making you all look bad?

Paul: $\quad$ It's not so easy as to say it's the younger people cos you'll always get older drivers that want to drive irresponsibly and speed. But it's a small percentage of the drivers down here that do give us a bad name. We've tried to tell them but like I said you can't beat them over the head. 
Association with Aberdeen's Beach Boulevard was also viewed as contributing towards their labelling by outside groups and Daniel believed that people would hold negative opinions of him if they knew he frequented Aberdeen's seafront:

\begin{abstract}
When you first asked me if I was a 'cruiser' and went to the Beach Boulevard I denied it until I found out the reason you were asking was that you were doing research. I didn't want folk to think I was someone who spends all their time at the beach even with their umbrella up and window rolled down in the rain when they're parked up. I only go there occasionally and those who are there all the time are quite sad. I don't want you thinking I'm like them (Fieldnotes, July 2005).
\end{abstract}

Ironically, as well as denying and rejecting the myth, they also support and reify it by labelling others as 'boy racers'. Thus as Goffman (1963: 45) notes, the stigmatized individual learns and incorporates the standpoint of the normal, acquiring thereby the identity beliefs of the wider society and a general idea of 'what it would be like' to possess a particular stigma. The drivers experienced and exhibited identity ambivalence' (Goffman, 1963) when they viewed members of the group behaving anti-socially or driving deviantly. In doing so, the deviant 'boy racers' were acting out the negative attributes imputed to them by society (see Goffman, 1963). Respondents were repulsed by the sight of group members behaving deviantly. As a result, their social and psychological identification with these offenders held them to what repelled them, 'transforming repulsion into shame, and then transforming ashamedness itself into something of which [they were] ashamed' (Goffman, 1963: 131-32). 
Informants viewed themselves as 'respectable' members of the subculture who took pride in their cars, their driving, and their adherence to the laws of the road and subcultural norms and values. They also took pride in their involvement with Grampian Police. In contrast, the law-breakers or outsiders were viewed as 'rough racers'; a minority who jeopardised the subculture and their use of the space at Aberdeen's seafront. They were seen to threaten the subcultural way of life adhered to by the 'respectable' participants. Hence, respectability proved to be an 'important lens' through which many respondents assessed themselves (Watt, 2006: 786) and it offered the drivers a positive identity. Respectability was not only of individual concern but became a matter of 'collective import' for members of the subculture (see Ball, 1970: 327). The drivers made strenuous efforts to distantiate themselves from the 'rough' elements around them and in doing so maintain their own respectability in straitened circumstances (Watt, 2006: 786-87). Hence, the actions of drivers to distance themselves from the myth of the 'boy racer' can be seen as attempts to 'normify' their own conduct but also clean up the conduct of others in the group; what Goffman (1963: 132) terms 'in-group purification'. The drivers I spoke to were keen to emphasise that they did not race, speed, or behave 'anti-socially'. These behaviours were attributed to others who were accused of 'letting the group down' by behaving badly. Respondents also attempted to normify the conduct of 'deviant' members of the group. The strategies for doing so included interacting with Grampian Police via the Drivers' Group, posting information on their websites which included the rules of participating at Aberdeen Beach, and through a form of in-group policing whereby members reported individuals to the police if they deemed their behaviour to be dangerous or anti-social. 


\section{Conclusion}

McRobbie and Thornton (1995) claim that a moral panic is a collective process involving the youth, media, moral entrepreneurs, control agents and public, who are 'accomplices in the action' (Young, 2007: 56). This analysis of the social reaction to 'boy racers' supports their argument. The car enthusiasts were involved in the process along with the outside groups. However, their argument that folk devils are less marginalized than they once were, and that they have the capacity to articulately support themselves in the mass media that castigates them, and that these interests are defended by their own niche and micro media, is not supported. The car enthusiasts in Aberdeen were marginalized by the media, other outside groups and the use of antisocial behaviour legislation. This further contributed to their stigmatization and the labelling of the subculture as 'deviant' and 'anti-social'. Although they attempted to communicate with the media in order to change the myth of the 'boy racer', these attempts were fruitless, thus illustrating the 'stickiness of labels' (Rosenhan, 1973). The car enthusiasts were aware of this, did not trust the media, and believed that they would use their comments for their own ends. It can also be argued that the car enthusiasts' acknowledgement of the symbol of the 'boy racer' in fact contributes to the myth of the 'boy racer'. Although they were keen to distance themselves from the label of a 'boy racer', they were able to identify individuals whom they believed were emblematic of this stereotype. Finally, although niche and micro media such as magazines and websites, play a crucial role in the organisation and rituals of this car

culture, and provide space for self-expression, these same media are themselves a focus of moral concern and indignation by the outside groups. They too, become caught up in the moral panic. Hence, this research also sheds light on the virtual 
aspect of contemporary moral panics. Inevitably, groups such as car enthusiasts will continue to be stigmatized and marginalised by the mass media, authorities, and politicians. Ironically, their own niche and micro media reifies the (ir)rationality for the moral panic.

' Coutts, G. (2006) 'Vow to Fight on to Beat Menace of Bouley Boys', Evening Express (26 March 2006) page 6.

${ }^{2}$ Press \& Journal 'The 80mph Madness of the Bouley Boys, But the Council Has Not Done a Thing About It' (21 August, 2002).

${ }^{3}$ The Dispersal of Groups power was used twice in the summer of 2005, to tackle Aberdeen's 'boy racers'. The Seizure of Vehicles power has been used across Scotland since 2005. In England and Wales anti-social behaviour legislation is enshrined in the Crime and Disorder Act (1998) and the Antisocial Behaviour Act (2003) whereas in Scotland it is contained in the Antisocial Behaviour etc. (Scotland) Act (2004).

${ }^{4}$ Terms used to describe female models that feature at car shows, in car magazines, and on Internet sites.

${ }^{5}$ Anonymous (2002) 'Gathering of City Boy Racers is Hailed as a Success', Press \& Journal (3 June 2003).

${ }^{6}$ Anonymous (2003) 'Police Campaign Aims to Scuttle 'Bouley Boys', Press \& Journal (28 July, 2003).

${ }_{7}^{7}$ Anonymous (2003) 'The High-Octane Problem That Just Won't Go Away', Press \& Journal (31 July, 2003).

8 Anonymous (2006) 'Drive Cuts Boy Racer Problems'. URL (consulted November, 2006): www.thisisnorthscotland.co.uk

9 Tout, J. (2007) 'Brakes Put on Boy Racers at Car Park'. URL (consulted May, 2007): www.thisisnorthscotland.co.uk

${ }^{10}$ Simpson, M. (2007) 'Bid to Drive through Deal between Boulevard Rivals', Evening Express (13 August, 2007: page 21.

${ }^{11}$ Walker, C. (2005) 'Peace on Agenda at Meeting', Press \& Journal (19 February, 2005).

${ }^{12}$ McClintock, K. (2005) 'Weapon in Bouley War', Evening Express (11 February, 2005).

13 Maddox, D. (2007) 'Boulevard Cameras Bill Shock', URL (consulted April, 2007): www.thisisnorthscotland.co.uk

14 Tout, J. (2007) ' $£ 180,000$ Bouley Blow', URL (consulted April, 2007): www.thisisnorthscotland.co.uk

${ }^{15}$ Anonymous (2003) 'The High-Octane Problem That Just Won't Go Away', Press \& Journal (31 July, 2003).

${ }^{16}$ Anonymous (2003) 'The High-Octane Problem That Just Won't Go Away', Press \& Journal (31 July, 2003).

${ }^{17}$ Anonymous (2006) 'We Cannot Let Boy Racers Win', Evening Express (23 March 2006) page 6.

${ }^{18}$ Anonymous (2003) 'Solving the Boy Racer Problem', Press \& Journal (25 July 2003).

${ }^{19}$ Anonymous (2003) 'Boy Racers Flaunt their Exploits on Website', Press \& Journal (11 March, 2003).

${ }^{20}$ Anonymous (2003) 'Ex-Officer Blamed For Tips to Speeders', Press \& Journal (9 May, 2003).

${ }^{21}$ Ritchie, G. (2004) 'New Websites Spark Fears of Street Racing: "Bouley Cruiser" Condemned', Evening Express (22 June, 2004).

${ }^{22}$ Subcultural term for an area at the seafront where the city's old tramlines still remain. It is here that the drivers park their cars in the evenings.

\section{References}

AITKEN, S. (2001) Geographies of Young People. London: Routledge. 
BALL, D.W. (1970) 'The Problematics of Respectability', in J.D. Douglas (editor)

Deviance \& Respectability: The Social Construction of Moral Meanings. New York:

Basic Books, pp.326-371.

BECKER, H. (1963) Outsiders. New York: Free Press.

BENGRY-HOWELL, A. (2005) Performative Motorcar Display. Unpublished PhD Thesis: University of Birmingham, UK.

BURNEY, E. (2005) Making People Behave. Devon: Willan Publishing.

COHEN, S. (1985) Visions of Social Control. Cambridge: Polity Press.

COHEN, S. (2002[1972]) Folk Devils and Moral Panics, 3rd edn. London: Routledge.

CROWN OFFICE (1986) Public Order Act. London: Stationary Office.

CROWN OFFICE (1998) Crime \& Disorder Act. London: Stationary Office.

CROWN OFFICE (2003) Antisocial Behaviour Act. London: Stationary Office.

CROWN OFFICE (2004) Antisocial Behaviour etc. (Scotland) Act. Edinburgh: Stationary Office.

DOUGLAS, M. (1966) Purity and Danger. London: Routledge.

FALCONER, R and KINGHAM, S. (2007) 'Driving People Crazy: A Geography of Boy Racers in Christchurch, New Zealand', New Zealand Geographer Vol. 63, pp.181-191.

FEELEY, M.M and SIMON, J. (2007) 'Folk Devils and Moral Panics: An Appreciation from North America', in D. Downes, P. Rock, C. Chinkin and C. Gearty (editors) Crime, Social Control and Human Rights. Devon: Willan Publishing. GOFFMAN, E. (1963) Stigma. London: Penguin. GOODE, E and BEN-YEHUDA, N. (1994) Moral Panics. Oxford: Blackwell. 
HIER, S. (2003) 'Risk and Panic in Late Modernity: Implications of the Converging Sites of Social Anxiety', British Journal of Sociology Vol.54, No.1, pp.3-20.

HOLLWAY, W and JEFFERSON, T. (1997) 'The Risk Society in an Age of Anxiety: Situating Fear of Crime', British Journal of Sociology Vol.48, No.2, pp.255-265.

JENKINS, P. (1999) Synthetic Panics. New York: New York University Press.

LEE, R.M. (1993) Doing Research on Sensitive Topics. London: Sage.

LUMSDEN, K. Rebels of the Road: A Sociological Analysis of Aberdeen's 'Boy Racer' Culture and the Societal Reaction to their Behaviour (Working title, due for completion May 2009). University of Aberdeen: Unpublished $\mathrm{PhD}$ thesis.

MCROBBIE, A and THORNTON, S. (1995) 'Rethinking "Moral Panic" for MultiMediated Social Worlds', The British Journal of Sociology Vol.46, No.4, pp.559-574. PRESDEE, M. (2000) Cultural Criminology and the Carnival of Crime. New York: Routledge.

REID, K. (2003) 'Law and Disorder: Victorian Restraint and Modern Panic', in J. Rowbotham and K. Stevenson (editors) Behaving Badly. Aldershot: Ashgate.

ROSENHAN, D.L. (1973) 'On Being Sane in Insane Places', Science Vol.179, pp. $250-258$.

TYLER, T and BOECKMANN, R. (1997) "Three Strikes and You're Out, But Why?" The Psychology of Public Support for Punishing Rule Breakers', Law and Society Review Vol.31, pp.237-265.

UNGAR, S. (2001) 'Moral Panic Versus the Risk Society: The Implications of the Changing Sites of Social Anxiety', British Journal of Sociology Vol.52, No.2, pp.271291. 
WATT, P. (2006) 'Respectability, Roughness and "Race": Neighbourhood Place Images and the Making of Working-Class Social Distinctions in London', International Journal of Urban and Regional Research Vol.30, No.4, pp.776-797.

WINLOW, S, HOBBS, D, LISTER, S and HADFIELD, P. (2001) 'Get Ready to Duck: Bouncers and the Reality of Ethnographic Research on Violent Groups', British Journal of Criminology Vol.41, pp.536-548.

YOUNG, J. (1971) The Drugtakers. London: Paladin.

YOUNG, J. (2007) 'Slipping Away - Moral Panics Each Side of the "Golden Age", in D. Downes, P. Rock, C. Chinkin, and C. Gearty (editors) Crime, Social Control and Human Rights. Devon: Willan Publishing. 